\title{
Unequal Allies?
}

United States Security and Alliance Policy

Toward Japan, I945-1960 



\section{Unequal Allies?}

United States Security and Alliance Policy

Toward Japan, I945-1960

John Swenson-Wright

S T A N F ORD UN I VERS I T Y PRES S

Stanford, California 2005 
Stanford University Press

Stanford, California

(C) 2005 by the Board of Trustees of the

Leland Stanford Junior University

Library of Congress Cataloging-in-Publication Data

Swenson-Wright, John.

Unequal allies? : United States security and alliance policy toward Japan, I945-I960 / John Swenson-Wright.

p. $\mathrm{cm}$.

Includes bibliographical references and index.

ISBN 0-8047-396I-7 (cloth : alk. paper)

I. United States-Foreign relations-Japan. 2. Japan-

Foreign relations-United States. 3. United States-Foreign

relations-I945-I953. 4. United States-Foreign

relations-I953-I96I. 5. National security-United

States-History-2oth century. 6. National security-

Japan-History—2oth century. 7. Alliances-History-2oth

century. I. Title.

EI83.8.J3S94 2005

$327.73052^{\prime} 09^{\prime} 045-\mathrm{dc} 22$

2004016215

Printed in the United States of America

Original Printing 2005

Last figure below indicates year of this printing:

$\begin{array}{llllllllll}\text { I4 } & \text { I3 } & \text { I2 } & \text { II } & \text { IO } & 09 & 08 & 07 & 06 & 05\end{array}$

Typeset at Stanford University Press in Io/I 3 Sabon 
FOR SOFIA 
